\title{
Revista "Polímeros: Ciência e Tecnologia" now also in Italy
}

In March 2006, the Brazilian Polymer Association (ABPol) signed a "Mutual Cooperation Agreement" with the Italian Association of Science and Technology of Macromolecules (AIM). The main item of this agreement is an exchange of articles that have been published in the magazines of the two associations. At least one article a year, among those appearing in the AIM Magazine, will be published by ABPol, and at least one article from the ABPol Magazine will in turn be published by AIM. The parties to the Accord also expect to share news and other items of mutual interest. The two associations have a lot in common and it is a matter of pride for the members of ABPol that work related to the Science and Technology of Polymers, carried out and published in Brazil, will also be reported in a European specialist publication.

The Italian Association of Science and Technology of Macromolecules (Associazione Italiana di Scienza e Tecnologia delle Macromolecole AIM) was founded in 1975 during a first National Congress, which took place in San Donato Milanese, in the Great Hall of the Conference Center of ENI (the Italian National Oil \& Gas Company).The purpose of AIM is to promote research and the study of macromolecules in all their scientific, technological and applied aspects. To this end, AIM organizes and promotes congresses, courses, workshops and seminars on the diverse areas that exist in the field of polymer studies, also handling the publication of educational material, be it for general or scientific readers, such as the AIM Magazine, the Annals of Congresses or "MeetingSchools", or the recent AIM University text book "Fundamentals of Polymer Science".

Nowadays, the Association has about 800 members coming, in practically equal numbers, from the academic world (Universities and Research Centers) and industry (including small and medium enterprises). For this reason, AIM represents a natural meeting point and place for dialogue between these two worlds that, despite so many common interests, are frequently characterized by quite different experiences, cultures, demands and perspectives.

The Executive Council of AIM has six members, four of whom are elected each two years, at the AIM Congress, the other two being: the President whose mandate has just ended and the Council-Member who received the highest vote in the preceding elections. This procedure has guaranteed the functional continuity of the Council. The newly-elected Executive Council meets and elects the new President, who normally should be the one with most votes; however, there exists an unwritten rule that the Presidency will alternate between members who come from industry and those who come from academia.

In 1975, AIM launched a very modest quarterly Bulletin, consisting of photocopied sheets, which circulated news of AIM's own activities. Its evolution was gradual: for some years the Bulletin was included in the widely-circulated magazine of the Italian Chemical Society, "Chemistry \& Industry". The Bulletin became a real Magazine in 1998, taking on the graphic layout which is known today and also preserving the original numbering that began with the first AIM Bulletin in 1975.

The magazine has an Editorial Board of four people, one of whom is the Chief Editor, while other collaborators are responsible for the several Sections. The members of the Board may go directly to specialists in the various sectors of academic or industrial research, asking for contributions on specific scientific topics for the magazine. However, in recent years, as many people ask for their articles to be published in the magazine, there is now a process of selection of the material submitted.

The Director with responsibility for AIM Magazine, Roberto Filippini Fantoni, interviewed in this edition of Polímeros, contributes articles on various subjects and closely follows all items published in the Magazine, being officially and legally responsible for its contents under the law that regulates publications in Italy.

What is your post or function in AIM and in the Magazine and when did you start to commit yourself to the Magazine? Also could you tell us about your educational background and your connection with Mazzaferro?

My current post is that of Director Responsible for AIM Magazine. In the past I have been a member and then Chair of the Technological Committee, for several terms of office, and a member of the Executive Council for two terms (four years).

In 1998 we decided to upgrade the Bulletin of the Association and register it officially with the authorities as a magazine, so we needed a Responsible Director enrolled in the Journalists Union. Among the members more involved in running the Association, I was the only one registered as a Journalist, so.......I was "pressed" to accept the job.

I graduated in pure chemistry and 
presented a thesis in the area of macromolecular chemistry in Milan, under Professor Mario Farina (who collaborated with Giulio Natta in the work on isotactic polypropylene that got him the Nobel Prize). But I was already working in the field of polymers (first at Ciba and later at other small local manufacturers) and especially in the polymerization of emulsions and acrylic solutions in the leather industry.

From 1973 to 1982 I did research at the SNIA Viscosa (later SNIA Tecnopolimeri) Research Center, where I worked on the polymerization of polyamides, particularly polyamide- 6 and related copolyamides. In 1982 I chose the path of consultancy and gave advice to a number of Italian and foreign companies, either in the field of polyamides or on the polymerization of acrylics and polyurethanes in emulsions (in Italy: Radici Group, Aquafil, PGroup and Nylco, Sipac, VEPI, F. Lamberti; abroad: Mazzaferro (BR), Fibra DuPont (BR), SNIAFA (ARG), Hong Lin (RPC).

Since 1995 I've taken part in the Supervision Board of the China Textile University (now renamed Dong Hua University), in the Chemical Engineering Department, where we have supervised doctoral research, centered on polyamide polymerization, for several postgraduates who are now getting established as lecturers at various universities in China and abroad. We have had a number of articles published in both Chinese and international journals. Since 2002, I've been responsible for a Short Course "Management of Research and Patents", part of an "Innovation Management" module at Bergamo University, in the Department of Industrial Engineering. My adventure with Mazzaferro, located in the ABC region of São Paulo, started with a consultancy on the manufacture of copolyamides in 1984. This was followed up with the planning of a new plant for continuous production of polyamide- 6 at low, medium and high viscosity. This close working relationship eventually turned into a permanent consultancy on research and development of new copolyamides.

\section{You make frequent trips to Brazil,} don't you? How did you meet and get involved with ABPol?

I already read the ABPol Magazine, but I really got to know the Association only when I took part in the latest Congress in Águas de Lindóia. In fact, it was by chance that I had the opportunity to contribute to that Congress. I was waiting at the check-in in Malpensa Airport, Milan, seeing off a technician

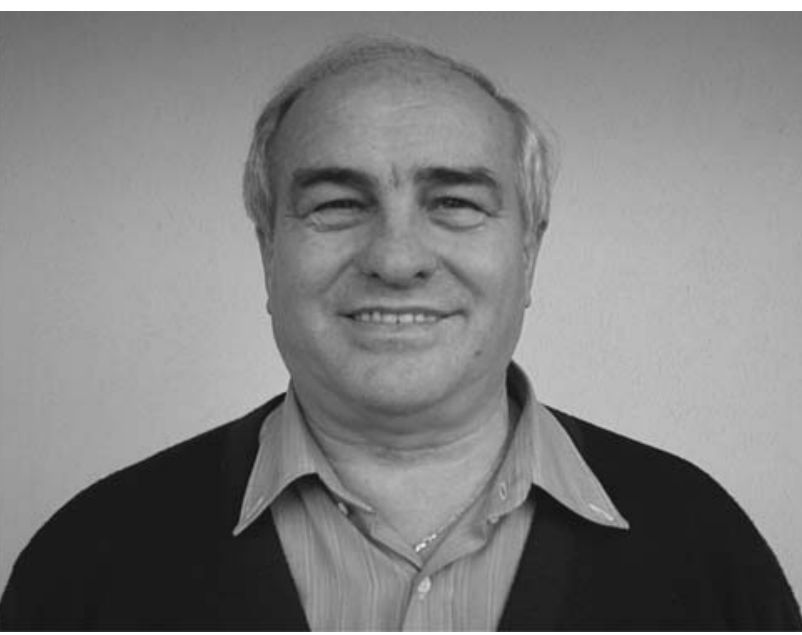

from Mazzaferro who was returning to Brazil after a working visit to Italy. Queuing in front of us was a Brazilian family who, noticing I was talking to a Brazilian in Portuguese (with this perceptibly different intonation), wanted to know how I came to speak Portuguese and we started to chat. Soon they discovered I was a consultant for Mazzaferro, a firm they knew, and I found out that the lady I was talking to was a lecturer at Unicamp, a university I knew well and where I'd given lectures on two occasions. She was Lúcia Innocentini Mei, a member of ABPol who was on the organizing committee of the Águas de Lindóia Congress.

Thus I came to participate as an Invited Guest. At the Congress, I conceived the idea of meeting one of the organizers of the ABPol magazine, and Lúcia introduced me to Súlvio
Manrich. We were soon on very good terms and subsequent developments flowed easily, so that the collaborative agreement between the two magazines came as a natural outcome.

\section{What do the two organizations have in common?}

The Italian Association of Science and Technology of Macromolecules (AIM) and the Brazilian Polymer Association (ABPol) have much in common, at least as far as their professed objectives are concerned. Both bodies organize events connected with the world of polymers: study meetings, biannual congress, technical workshops and so on. Both publish or sponsor books in the field of macromolecules. Both have a high-quality magazine, albeit with differing editorial policies.

\section{What are the main differences between the editorial approaches of AIM Magazine and Polímeros: Ciência e Tecnologia?}

The substantial difference between the magazines lies, in fact, in the editorial line. At AIM we decided that there were already plenty of Italian and international polymer magazines and that one more of the same would not be especially interesting. Hence we staked the success of the magazine on the Polymers \& Life section, in which we discuss current affairs or general interest topics that somehow relate to polymers. We talk about EPO found in cyclists' blood, about the history of rubber erasers, about the hydrocarbon polymers synthesized in the atmosphere on Titan, the BSA of mad cows, the basic polymer constituting amber, the macromolecular structure of the sticky parts of lizards' feet, the synthesis of poly(formaldehyde) in the tails of comets and many other topics like these. This idea was a great success, so we kept following the same path. It 
was such a success that the EPF (European Polymer Federation) considered AIM Magazine to be the most interesting of the various journals of the European Polymer Associations. As a consequence, we were given the job of editing a unique special number, in English, published in July 2001 with the title: "Polimeri in Europe - Quo vadis?"

The articles published in Polimeros: Ciência e Tecnologia are very interesting and of a high scientific and technological standard. Moreover, they are more accessible to Brazilian readers than publications in English and, therefore, more useful from an educational point of view. The ABPol magazine is first-rate in its typography and the graphic layout is very carefully done. From this point of view, the two magazines are certainly on an equal footing.

\begin{abstract}
AIM and ABPol have recently signed an agreement of exchange between their respective magazines, with the effect that articles and other published material considered of interest to a wider readership will be swapped.
\end{abstract} What is the relevance of this arrangement for the two bodies?

The relevance of this kind of international agreement is fairly obvious and I hardly need spell it out. Certainly, it serves to underline the important role the polymer sector plays in both societies. For us in Italy, it will make clear to AIM readers that the polymer-related industrial world in the Brazilian territory is a large and influential sector that backs ABPol completely, both financing and organizing its activities. This might stimulate the Italian polymer industry, which nowadays is suffocated, owned by transnationals, and less and less willing to give concrete support to AIM initiatives.

The style of the articles from AIM Magazine that will be published in Polímeros: Ciência e Tecnologia is so different that they can't fail to stimulate the readers with their diversity. For their part, the articles from Polimeros that will appear in AIM Magazine are certain to project a strong involvement in science and technology that I am sure will take Italian readers by surprise, accustomed as they are to imagine Brazil as a the country of samba and carnival or, conversely, of shantytowns of the dispossessed, without giving due consideration to its been published for the last 15 years and has maintained an editorial policy of including news and announcements, diary of events, interviews and educational, technical and scientific articles. What kind of material will, generally speaking, interest the members of AIM?

Actually, the readers of AIM Magazine are used to reading anything related to polymers. Reiterating the ideas I've just been putting forward, the articles chosen should obviously be of a good scientific or technological standard but, above all, they should deal with very topical concerns in the macromolecule world.

Say a few words about the types of article or text published in the AIM Magazine.

The articles are connected with everyday life: remedies in which macromolecules are involved, the existence of macromolecules in deep space within the solar system, natural materials made of macromolecules ...... There is also a section that deals with chemical products in general, not necessarily macromolecules, but which do play a part in our lives. The Magazine obviously has a space reserved for AIM ac- impressive scientific and technological development. Just as the typical Brazilian stereotype is all frivolity and football, we Italians have to put up with the "mafia, pizza and mandolin" image.....all very quaint, but a problem for both of us!

ABPol takes pride in being able to send information generated in Brazil across its borders and have it published in a country like Italy. The magazine Polímeros: Ciência e Tecnologia has tivities and subsequent reports and commentaries. There is a further section for announcements of all the events concerning macromolecules (Conferences, Courses, Fairs, etc) and a part reserved for Small and Medium Manufacturers.

We even have a Recipe section, which seems to be well received, especially among young polymer chemists, who need to show off their cooking skills as they leave home and move into shared lodgings or get married. 


\section{How can the Members of ABPol and AIM contribute to this partnership?}

This is not an easy question to answer because really, beyond the formally agreed intention to exchange at least one article a year and to keep each other informed about our respective high-level activities, especially international ones, it will be rather hard to involve many $\mathrm{ABPol}$ and AIM members directly. However, given the large number of technical staff and research-workers of Italian origin living in Brazil, we could consider a historical project in which they might tell briefly the story of their family, from Italy to Brazil. The emerging historical material could then be published simultaneously in AIM Magazine and Polímeros: Ciência e Tecnologia, in a special ItaloBrazilian edition. Obviously everything would have to be discussed and we are open to any suggestion.

\section{Would you like to make any further remarks?}

My first comment is about the considerable difference between the organization of ABPol and AIM and their two magazines. The Brazilian organization has appreciably more staff, with a remarkable number of members in both the Executive Council and the Committees. Furthermore, regarding the magazine, there is a very large number of members on the Editorial Board and the Editorial Committee. Even the articles are finely combed in a rigorous process of selection, a sign that a large number of authors want to publish in the Brazilian magazine. In our case, the permanent referees of the Magazine are few, overworked and highly qualified, and the articles, owing to the editorial policy that has been chosen, have to be picked carefully: it isn't always easy to find an expert in a subject so far from the usual technical material.

The support from the Brazilian industrial sector is truly remarkable and this allows a bigger budget than we have at AIM, whose lack of industrial support is more evident each day. Despite these financial problems, AIM is proud to have succeeded in organizing annually - for more than 30 years in Gargnano (a lovely little town on the banks of Lake Garda) - a five-day Meeting-School, attended by dozens of young people, from industry, universities and the National Research Council. Each year, a different topic is debated, and the sessions are almost always full (100-120 people, the maximum capacity of the main meeting hall). I myself was a 'student' of that School, before becoming a lecturer.

In the same place, during the week immediately preceding or following this event, AIM and EPF organize EUPOC (the Europolymer Conference), which also lasts for five days. The chosen theme is again different each year, and the best international specialists in that area take part in EUPOC.

Over these two weeks a separated event denomined "Young Macro" is organized by young scientists from the field of macromolecules, who show their work in mini-presentations and seminars and discuss common problems, such as how to get a job after graduating or completing a doctorate. This question is a critical one, given the shortage of companies in this sector with capacity to absorb new graduates and doctors.

Thus we have two contrasting Associations, with quite different organizational capacities, but I believe that this joint initiative will bring many benefits to both. This could be the start of future collaborative ventures across the ocean that draw our two countries closer; after all, our traditions and customs are not so far apart, owing to our common Latin culture.

Entrevista realizada pelo Prof. Silvio Manrich, sócio honorário da ABPol. 